\title{
Application of Electrospray Mass Spectrometry in Probing Protein-Protein and Protein-Ligand Noncovalent Interactions
}

\author{
Eric C. Huang, Birendra N. Pramanik, Anthony Tsarbopoulos, \\ Paul Reichert, Ashit K. Ganguly, Paul P. Trotta, and \\ Tattanahalli L. Nagabhushan \\ Schering-Plough Research Institute, Kenilworth, New Jersey, USA
}

Thomas R. Covey

Sciex, Inc., Thornhill, Ontario, Canada

\begin{abstract}
A novel mass spectrometry-based methodology using electrospray ionization (ESI) is described for the detection of protein-protein [interferon (IFN)- $\gamma$ dimer] and protein-ligand [ ras-guanosine diphosphate (GDP)] noncovalent interactions. The method utilizes ESI from aqueous solution at appropriate $\mathrm{pH}$. The presence of the noncovalent complex of the IFN- $y$ dimer was confirmed by the observed average molecular weight of 33,819 Da. The key to the detection of the IFN- $\gamma$ dimer is the use of an alkaline solution $(\mathrm{pH} \sim 9)$ for sample preparation and for mass spectrometry analysis. The effect of the declustering energy in the region of the ion sampling orifice and focusing quadrupole on the preservation of the gas-phase noncovalent complex (IFN- $\gamma$ dimer) was also studied. The effect of the declustering energy on complex dissociation was further extended to probe the noncovalent protein-ligand association of ras-GDP. It was found that little energy is required to dissociate the IFN- $y$ dimer, whereas a substantial amount of energy is required to dissociate the gas-phase ras-GDP complex. (J Am Soc Mass Spectrom 1993, 4, 624-630)
\end{abstract}

S ome of the most significant advances in mass spectrometry technology in recent years have been in the development and application of new ionization techniques. Application of mass spectrometry to the characterization of compounds with molecular weights greater than $1000 \mathrm{Da}$ was rare prior to the development of desorption ionization methods. These developments include field desorption [1], fast-atom bombardment [2, 3], and plasma desorption [4-7]. More recently, matrix-assisted laser desorption [8, 9] and electrospray ionization (ESI) [10-12] processes have appeared as new technology for high-mass analysis by mass spectrometry. Mass spectrometry exhibits a variety of unique capabilities for a broad range of applications and is commonly used for solving bioanalytical problems when high sensitivity and structural information are required [13]. The newly developed technique of ES/MS, which allows the formation of gas-phase macromolecular ions directly from solution at atmospheric pressure via ion evaporation [14, 15], represents an important advancement in mass spectrometry technology that significantly extends the

Address reprint requests to Birendra N. Pramanik, Schering-Plough Research Institute, 2015 Galloping Hill Road, Kenilworth, NJ 07033. range of mass spectrometry applications to the field of biomedical research $[16-20]$.

Traditionally, mass spcctrometry-based research in the field of noncovalent interaction between biomolecules has been considered difficult, if not impossible, mainly owing to the incompatible experimental requirements. The unique feature that sets ESI apart from the rest of the available ionization techniques is that it utilizes highly charged liquid droplets as the ion evaporation medium, allowing the sample being analyzed to remain in its solution form prior to mass spectrometry analysis $[10,13,15]$. The obvious advantage is that a protein sample can be introduced directly from solution in its biologically active form for mass spectrometry analysis. Ganem et al. [21, 22] reported the first application of ES/MS for noncovalent binding between FKBP (an immunosuppressive binding protein) and immunosuppressive agents (FK506 and rapamycin) and the enzyme-substrate interaction in which the enzymatic reaction of hen egg-white lysozyme with various substrates were studied. More recently, the observation of a ternary complex between the dimeric enzyme human immunodeficiency virus-1 protease and a substrate-based inhibitor was also reported [23]. We have been studying the noncovalent 
interaction of human ras protein with its guest ligands guanosine diphosphate (GDP) and guanosine triphosphate (GTP), and the successful ES/MS detection of the ras-GDP noncovalent complex has recently been reported [24]. The experimental conditions have been further refined by the use of a biological butfer solution to stabilize the noncovalent complexes of ras-GDP and ras-GTP in solution prior to mass spectrometry analysis [25].

An extension of this research is the feasibility study of using ES/MS for probing the noncovalent interaction between protein molecules. We used interferon (IFN)- $\gamma$ as the protein-protein interaction model for this purpose. IFN- $\gamma$ is a protein that exerts virus-nonspecific antiviral activity, at least in homologous cells, through cellular metabolic processes involving synthesis of both RNA and protein. IFN- $\gamma$, also known as macrophage-activating factor, is commonly named "immune" or type-II IFN. Its primary natural source is $\mathrm{T}$ cells. Both helper $\left(\mathrm{CD4}^{+}\right)$and cytotoxic $\left(\mathrm{CDB}^{+}\right) \mathrm{T}$ cells have the capacity to produce IFN- $y$ after activation with anti-CD3 [26].

Despite the different biological properties of IFN- $\gamma$, it is a lymphokine with potent immunomodulatory activities in addition to its antiviral role. IFN- $\gamma$ is unique among the interferons in activating macrophages and in the induction of class II molecules of the major histocompatibility complex. The activation macrophages are important in the killing of intracellular parasites and possibly tumor cells in vivo. The induction of class II molecules may facilitate antigen presentation to helper $\mathrm{T}$ cells, although inappropriate expression may be implicated in the development of autoimmune disease.

Human IFN- $\gamma$ is available in a pure form as a result of recombinant DNA technology and has been coded in both prokaryotes, such as Escherichia coli, and eukaryotes, such as Chinese hamster ovary and yeast cells. Mature IFN- $y$ is a protein of 143 amino acids $(\sim 17 \mathrm{kDa})$ with an excess of basic amino acid residues. The active form of this protein is a homodimer and is also known to be both heat and acid labile [27].

In this report, we describe the use of electrospray ionization for the detection of the biologically active IFN- $\gamma$ dimer. The effect of the ion sampling orifice potential (OR) on the mass spectrometry detection of the noncovalent IFN- $y$ dimer and its charge-state distribution is also discussed. This study is further extended to probe the protein-ligand interaction of ras-GDP.

\section{Experimental}

\section{Preparation of Human Interferon- $\gamma$}

The IFN- $\gamma$ used in these studies was recombinant human IFN- $\gamma$ D expressed in E. coli containing an initiator methionine at the $\mathrm{N}$-terminus [theoretical average molecular weight (MW) is 16,907.4 Da]. A 10-L scale fermentation was purified by a conventional purification process similar to that described previously in detail tor murine recombinant IFN- $\gamma$ [28]. 'I he initial cell extract was treated with polyethylene imine for precipitation of subcellular particles and large fragments of nucleic acids, resulting in a clear supernatant. Further purification was obtained by binding to phenyl-Sepharose, followed by elution with ethylene glycol. A cation-exchange chromatography step on carboxymethyl-Sepharose was required for removal of proteolytic fragments as well as certain E. coli contaminants. Following concentration by ultrafiltration, a gel filtration chromatography step using Sephadex G-100 was performed to separate components on the basis of MW. Fractions were combined that corresponded to the noncovalent dimeric form weighing approximately $32,000 \mathrm{Da}$. Subsequent analysis of the $\mathrm{N}$-terminus confirmed the presence of $\mathrm{N}$-terminal methionine followed by the predicted sequence for human IFN- $\gamma$. The resulting preparation was dialyzed against USP water and lyophilized to the free base and was utilized in all mass spectrometry studies. The resulting preparation was also analyzed by the cytopathic effect inhibition assay utilizing encephalomyocarditis (EMC) virus and L929 cells, as previously described [29], with human recombinant IFN- $\alpha-1$ as a standard. Titers for the latter were calibrated against a reference standard of natural human leukocyte IFN using EMC virus and human foreskin fibroblast cells (FS-71). Protein concentrations were determined according to Bradford [30] using bovine serum albumin as standard. The subsequently derived specific bioactivity was consistent for a homogenous IFN- $\gamma$ preparation; $2 \times 10^{6} \mathrm{IU} / \mathrm{mg} \mathrm{P}$. All chromatographic materials were obtained from Pharmacia Fine Chemical (Uppsala, Sweden).

\section{Preparation of Cytochrome $c$ Solution}

Horse heart cytochrome $c$ was purchased from Sigma Chemical Co. (St. Louis, MO) and was used without further purification. The stock solution of cytochrome $c$ was prepared in solution of $\mathrm{pH} \sim 9.3$ (adjusted by $30 \% \mathrm{NH}_{4} \mathrm{OH}$ ) to a final concentration of $4 \times 10^{-4} \mathrm{M}$. A second cytochrome $c$ solution was prepared by diluting the stock solution of cytochrome $c$ with the same solvent $(\mathrm{pH} \sim 9.3)$ to a final protein concentration of approximately $70 \mu \mathrm{M}$.

\section{Preparation of H-ras-GDP Complex}

C-terminally truncated normal human $\mathrm{H}$-ras (1-166) was expressed in $E$. coli from a synthetic ras gene under the control of both the $\mathrm{lpp}$ and taq promoters [31]. The noncovalently bound ras-GDP complex was subsequently purified from fermentor-grown, isopropyl- $\beta$-D-thiogalactopyranoside-induced cells by the previously reported procedure [32]. The stock solution $(\sim 20 \mu \mathrm{g} / \mu \mathrm{L})$ of ras-GDP complex (FPLC iso- 
lated sample) was kept in a solution containing $64 \mathrm{mM}$ Tris $\mathrm{HCl} \mathrm{pH} 7.6,10 \mathrm{mM} \mathrm{MgCl}, 1 \mathrm{mM} \mathrm{NaN}_{3}, 0.5 \mathrm{mM}$ dithioerythritol, and $250 \mathrm{mM} \mathrm{NaCl}$. For mass spectrometry analysis, the stock solution was further diluted to a final concentration of approximately 2 $\mu \mathrm{g} / \mu \mathrm{L}$. All sample solutions were stored at $4{ }^{\circ} \mathrm{C}$ prior to mass spectrometry analysis. The activity of the ras protein in GDP binding assays and GTPase assays was comparable to previously published data [32-34]. Details of the experimental conditions for stabilizing the noncovalent complexes have been described elsewhere $[24,25]$.

\section{Mass Spectrometry}

A Sciex API III triple quadrupole mass spectrometer equipped with a standard atmospheric pressure ionization source (Sciex, Inc., Thornhill, Ontario, Canada) was used to sample ions produced from the ESI interface. In this system, ions were sampled into the vacuum for mass analysis through a $125-\mu \mathrm{m}$ i.d. orifice at the end of a cone extending toward the atmosphere. The atmosphere-to-vacuum transition occurs through this orifice without an intermediate differentially pumped region. The atmospheric side of the sampling cone was bathed with a curtain of high-purity dry nitrogen gas $(\sim 0.7 \mathrm{~L} / \mathrm{min})$, which acted both as a barrier to restrict contaminants and solvent vapor from entering the mass spectrometer varumm chamber and as an ion-molecule declustering region. High vacuum was maintained by cryogenically cooled surfaces maintained at $15-20 \mathrm{~K}$.

The mass analysis was carried out by scanning either the first quadrupole (Q1) or the third quadrupole (Q3) from 800 to $2400 \mathrm{Da}$ at a typical scan rate of 4 $s /$ scan. The sample, in its liquid form, was introduced either through direct infusion of solution or by flow injection via a Rheodyne external loop injector with a preselected solvent system. In the latter case, an Applied Biosystems, Inc. (Foster City, CA) model 140A dual-syringe micro liquid chromatography pump was used to deliver a constant liquid flow of 5-100 $\mu \mathrm{L} / \mathrm{min}$.

\section{Results and Discussion}

\section{Interferon- $\gamma$}

To our knowledge, there has been no report of any successful mass spectrometry detection of the dimeric form of IFN- $\gamma$. Our earlier attempts to analyze the IFN- $\gamma$ dimer under typical ESI conditions (i.e., 50\% MeOH, $0.1 \%$ trifluoruacetic acid, $\mathrm{pH} \sim 2.5$ ) resulted in an observed mass spectrum with a well-defined "bellshaped" multiply charged ion distribution (from +8 to +22 charges, data not shown) whose MW (16,910 Da) corresponded to the monomeric IFN- $\gamma$. In principle, the multiple charging phenomenon that occurs with ESI can have a strong denaturing effect through simple charge repulsion that destroys the higher order interactions, which are essential for protein-protein association; however, we have observed that with special sample handling, the specific protein-protein noncovalent dimer can be preserved in the gas phase.

Experience gained from our earlier study of ras-GDP and ras-GTP noncovalent complexes [24, 25] prompted us to further examine the IFN- $\gamma$ dimer with aqueous solution (i.e., no organic cosolvent added) at different $\mathrm{pH}$ conditions. Figure 1 shows the mass spectrum of the IFN- $y$ dimer in distilled water with a measured $\mathrm{pH}$ of approximately 6.7 . The mass spectrum reveals that the IFN- $\gamma$ dimer was dissociated on mass spectrometry analysis at a solution $\mathrm{pH}$ of 6.7 . Because isoelectric focusing indicated that the protein has a pI value of higher than 9 , a fresh protein solution was prepared, and its mass spectrum subsequently recorded in aqueous solution adjusted to a $\mathrm{pH} \sim 9$ with $30 \% \mathrm{NH}_{4} \mathrm{OH}$. Interestingly, the dimeric form of IFN- $\gamma$ (observed MW 33,819 Da) was preserved and successfully detected by mass spectrometry under these conditions (Figure 2a).

The MW determination of protein complexes composed of identical subunits (i.e., homodimer in contrast to heterodimer) requires special attention. Heterodimers can be readily distinguished from their monomeric components by the different multiply charged ion distributions that give rise to two different average MWs; however, the ion distribution and observed mass-to-charge ratio values for the monomeric form of a homodimer will overlap with the even charge states of its dimeric counterpart. The key to determining the presence of a protein homodimer is the detection of signals corresponding to its multiply protonated add charge states [35]. Careful examination of ions observed in Figure $2 \mathrm{a}$ reveals that these ions correspond to the various multiply charged states of

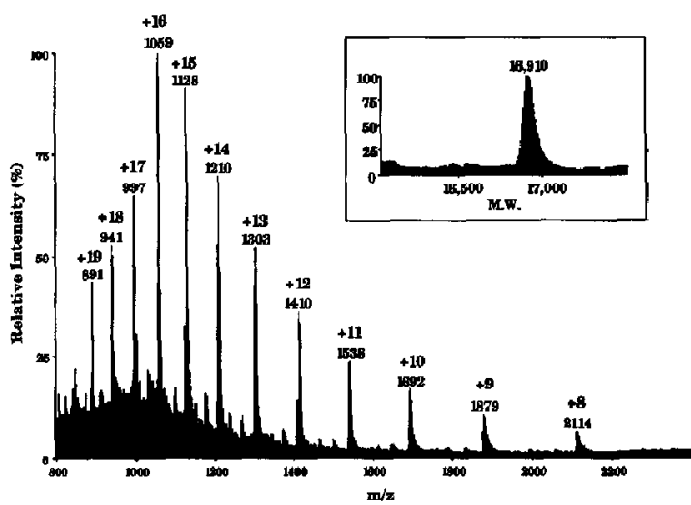

Figure 1. Full-scan ( $800-2400 \mathrm{Da}$ in $4 \mathrm{~s})$ ES mass spectrum of the IFN- $\gamma$ dimer noncovalent complex obtained from aqueous solution ( $\mathrm{pH} \sim 6.7$ ). The spectrum shows a multiply charged ion distribution ranging from +8 to +22 charges. The observed molecular weight (MW) $16,910 \mathrm{Da}$ (inset), which corresponds to the IFN- $\gamma$ monomer. No IFN- $\gamma$ dimer was detected under these conditions. 


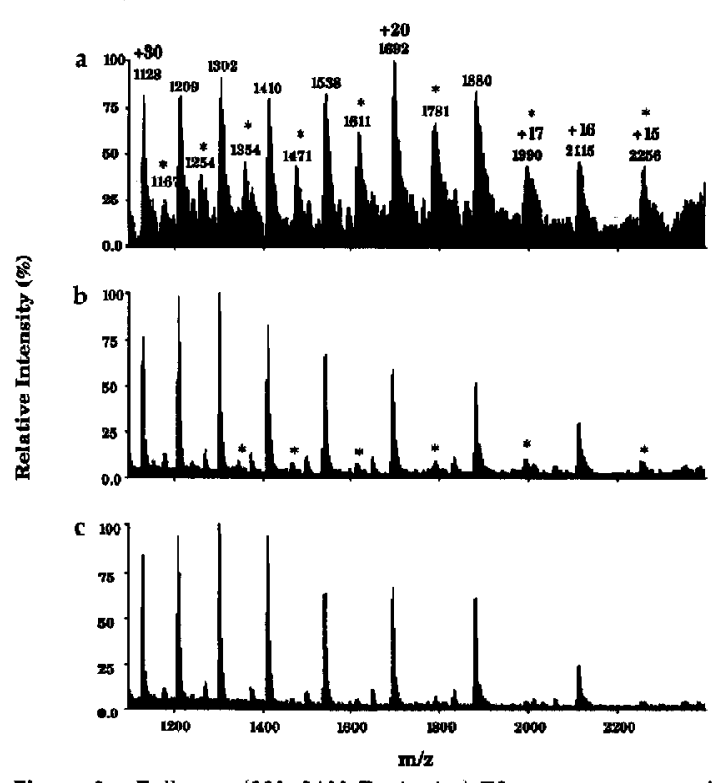

Figure 2. Full-scan ( $800-2400 \mathrm{Da}$ in 4 s) ES mass spectrum of the IF $\mathrm{N}-\gamma$ dimer noncovalent complex obtained from aqucous solution $(\mathrm{pH} \sim 9)$. (a) at $\mathrm{OR}=50 \mathrm{~V}$, the IFN- $\gamma$ dimer was detected by the observation of the corresponding multiply charged ions with charge states of +15 to +30 . (b) at OR $=70 \mathrm{~V}$, the IFN- $\gamma$ dimer signals have decreased dramatically. (c) At OR $=$ $100 \mathrm{~V}$, the IFN- $\gamma$ dimer has almost disappeared from the spectrum. For easy comparison, the odd charge states are denoted by an asterisk.

the dimeric IFN- $\gamma$. The observed values of $m / z$ 2256, $2115,1990,1880,1781,1692,1611,1538,1471,1410$, $1354,1302,1254,1209,1167$, and 1128 are assigned as the charge states of 115 to | 30, respectively. For easy comparison, the odd charged ions in Figure $2 \mathrm{a}-\mathrm{c}$ are denoted by an asterisk.

It has been shown, with horse heart cytochrome $c$, that random protein aggregation can occur because of high protein concentration [36]. To rule out the potential of forming a protein dimer via the concentration effect, the mass spectrometry detection of the IFN- $\gamma$ dimer was further investigated. First, horse heart cytochrome $c$ was analyzed at high concentration $(4 \times$ $\left.10^{-4} \mathrm{M}\right)$ by ES/MS. The solvent and mass spectrometry operation parameters were the same as those used to obtain the spectrum in Figure 2a. The observed signals (Figure 3a) at $m / z$ 2061, 1766, 1546, and 1374 correspond to the $+6,+7,+8$, and +9 charge states, respectively, of monomeric cytochrome $c$. In addition, signals corresponding to the odd charges $(+11$ and +13 ) of the cytochrome $c$ dimer were also detected at $m / z 2248$ and 1902, respectively. When the protein concentration was diluted to approximately $70 \mu \mathrm{M}$, no signals corresponding to the odd charges of the cytochrome $c$ dimer were detected (Figure $3 b$ ). Next, an equal molar mixture of IFN- $\gamma$ dimer and cytochrome $c$ (each at a final concentration of $35 \mu \mathrm{M}$ ) was prepared, and the mass spectrum was recorded (Figure $3 \mathrm{c}$ ). In

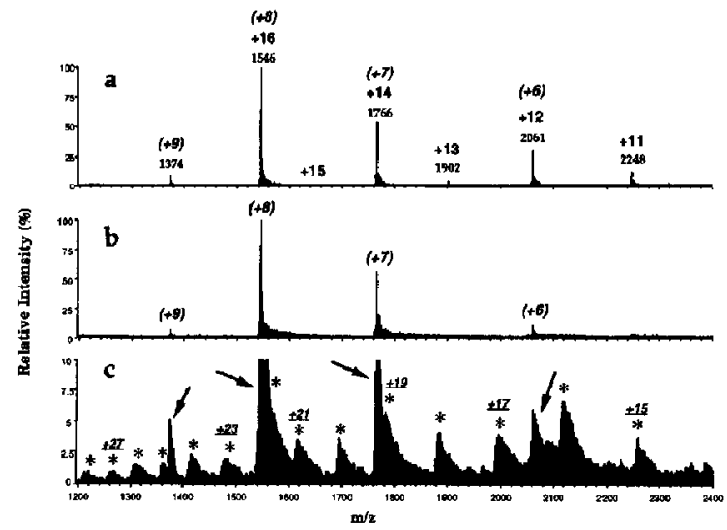

Figure 3. Full-scan (1200-2400 Da in 4 s) ES mass spectrum of (a) horse heart cytochrome $\mathrm{c}$ obtained from aqueous solution $\mathrm{pH}$ -9.3). At $\mathrm{OR}=50 \mathrm{~V}$, the cytochrome $c$ dimer resulting from high protein concentration $\left(4 \times 10^{-4} \mathrm{M}\right)$ was detected by the observation of the corresponding +11 and +13 multiply charged ions at $m / z 2248$ and 1902, respectively, numbers in parentheses correspond to the different charge states of the monomeric cytochrome $c$. (b) ES mass spectrum of horse heart cytochrome $c$ obtained from diluted aqueous solution ( $\mathrm{pH} \sim 9.3$ ) with a final concentration of approximately $70 \mu \mathrm{M}$. (c) ES mass spectrum obtained from an equal molar mixture (final concentration of approximately $35 \mu \mathrm{M}$ each) of IFN- $\gamma$ dimer and horse heart cytochrome $c(\mathrm{pH} \sim 9.3)$. The IFN- $\gamma$ dimer signals are denoted by an asterisk; signals corresponding to cytochrome $c$ are indicated by an arrow.

addition to the IFN- $\gamma$ dimer, signals corresponding to the $+6,+7,+8$, and +9 charge states of cytochrome $c$ ( $m / z 2016,1766,1546$, and 1374 , respectively) were detected. As expected, no signals of the cytochrome $c$ dimer were observed. Furthermore, signals corresponding to the random attachment between IFN- $\gamma$ and cytochrome $c$ were also absent. This result further confirmed that the IFN- $\gamma$ dimer detected by mass spectrometry under these experimental conditions was the specific noncovalent IFN- $\gamma$ dimer and was not the result of the random dimerization due to the concentration effect.

Our observation of forming the multiply charged positive ions in ESI with the protein sample prepared in alkaline solution ( $\mathrm{pH} \sim 9$ ) is consistent with other studies [37] in which myoglobin, lysozyme, and lactalbumin were used as protein standards. On the basis of their observations, these investigators suggested that ionization processes other than the simple evaporation of preformed solution ions are involved in ESI. More important, our finding indicates that the protein noncovalent dimer can survive the electrostatic repulsions exerted by the multiply charged ions generated by ESI.

Following the successful detection of the noncovalent complex of the IFN- $y$ dimer, the energy required to break apart this protein protein interaction was next investigated. Mass spectra were recorded of the IFN- $\gamma$ dimer solution $(\mathrm{pH} \sim 9)$ at different OR settings from 40 to $200 \mathrm{~V}$ (see Figure $2 \mathrm{a}-\mathrm{c}$ for the resul- 
tant mass spectra at low, medium, and high OR voltages). The percentage of the dimeric form was calculated from the change in ion intensity corresponding to the odd charge states of the IFN- $\gamma$ dimer. This ratio of ion intensity was then normalized against the value obtained at $\mathrm{OK}=50 \mathrm{~V}$. (Note: We did not detect any protein-related signal at $\mathrm{OR} \leq 40 \mathrm{~V}$.) The percentage of IFN- $\gamma$ in the dimer form thus obtained is not an absolute value; rather, it should be treated as a relative measurement of preservation of the protein dimer on change in the OR setting. Figure 4 shows the percentage of the IFN- $\gamma$ dimer observed in the experimental OR setting. Unlike the ras-GDP noncovalent complex system discussed later, dissociation of the IFN- $\gamma$ noncovalent dimer was triggered by an OR setting as low as $60 \mathrm{~V}$. The decrease in the dimer present in the spectrum was found to be a linear function of the OR setting. At $O R=130 \mathrm{~V}$, virtually no IFN- $\gamma$ was present as a dimer. These results imply that dissociation of the gas-phase IFN- $y$ dimer requires very little energy. Because both IFN- $\gamma$ subunits have the same number of protonation sites, the charges resulting from ESI should be distributed equally on the dimer molecule. Therefore, the electrostatic repulsion forces within the gas-phase noncovalent dimer of the highly charged IFN- $\gamma$ subunits may facilitate dimer dissociation at low OR settings. This also has the implication that at $\mathrm{OR}=50 \mathrm{~V}$ (i.e., the lowest orifice potential we used), the gas-phase IFN- $\gamma$ dimer might already be partially dissociated, making the use of this mass spectrometry methodology in determining solution-phase noncovalent association/dissociation constants more difficult.

\section{ras-GDP Noncovalent Complex}

ras Protein is a G-protein involved in the regulation of cell growth and differentiation. It is known that when

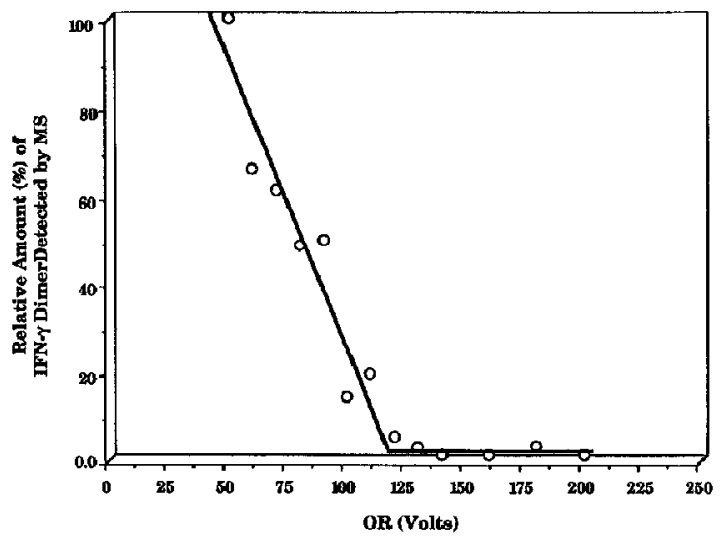

Figure 4. Effect of OR on the gas-phase IFN- $\gamma$ dimer noncovalent complex, showing the percentage of the IFN- $\gamma$ dimer detected by mass spectrometry from protein solution $(\mathrm{pH} \sim 9)$ at different orifice voltages. At $\mathrm{OR}=133 \mathrm{~V}$, virtually no IFN- $\gamma$ dimer was present. ras is bound to GTP, it becomes biologically active, initiating cell growth and differentiation, and when bound to GDP, it is inactive [38-40]. Mutant ras proteins deficient in the ability to change from GTP- to GDP-bound states have been implicated in uncontrolled cell growth. Therefore, the ability to difterentiate GDP-bound ras from GTP-bound ras is of importance in the study of uncontrolled cell growth. The noncovalent complex of ras-GDP has been detected by ES/MS with a recorded MW of 19,295 Da [24]. The noncovalent ras-GTP complex was also detected by ES/MS with the observed MW of $19,375 \mathrm{Da}$, and details of this work have been reported elsewhere [25]. The best condition for achieving optimum mass spectrometry sensitivity and signal stability for these complexes was found at a solution of $\mathrm{pH}-4$ without any organic cosolvent added.

As discussed earlier, dissociation of the gas-phase noncovalent IFN- $\gamma$ dimer can be induced by simply increasing the OR setting. The same experiment can also be applied to study the GDP ligand-binding affinity with its host ras protein. Therefore, the effect of this collisional exritation in the derlustering region on the observation of the ras-GDP noncovalent complex was investigated. To achieve this, the mass spectrum of ras-GDP was recorded from a sample solution of $\mathrm{pH} \sim 4$ while the OR voltage was varied from 40 to as high as $200 \mathrm{~V}$. The resultant mass spectra at low (40 $\mathrm{V})$, medium $(120 \mathrm{~V})$, and high (200 V) OR settings are shown in Figure $5 \mathrm{a}-\mathrm{c}$. At $\mathrm{OR}=40 \mathrm{~V}$, the mass spectrum revealed only signals of the ras-GDP complex; no signals corresponding to the apo-ras protein were detected, indicating no dissociation of the ras-GDP noncovalent complex. Surprisingly, the noncovalent complex of ras GDP was observed as one of the major components, even at the OR setting of $200 \mathrm{~V}$. This could be the result of electrostatic attraction between the oppositely charged GDP and ras protein molecules, causing the complex to appear more stable than expected. The multiply charged ion distribution was centered at the +11 charge state for $O R=40 \mathrm{~V}$ and was found to be the same for OR as high as $120 \mathrm{~V}$. The center of this charge distribution shifted to the +10 charge state when OR was increased to $140 \mathrm{~V}$. Further increase in the voltage $(160,180$, and $200 \mathrm{~V})$ resulted in a shift of the charge-state center to the +9 charge state. The change in the observed multiple charge distribution pattern at different $O R$ settings $(40-200 \mathrm{~V})$ is considered minor.

Although the charge distribution changed very little (from +11 to +9 charges) with respect to $O R$, the relative amount of the ras-GDP signals was highly affected by the different $O R$ settings (Figure 6). At $\mathrm{OR}=200 \mathrm{~V}$, three major components were observed with determined average MWs of $19,295,18,930$, and $18,852 \mathrm{Da}$, respectively. The MWs of 19,295 and 18,852 represent the ras-GDP complex and the unbound aporas protein, respectively, whereas the origin of the other $18,930-\mathrm{Da}$ component is not understood at the 

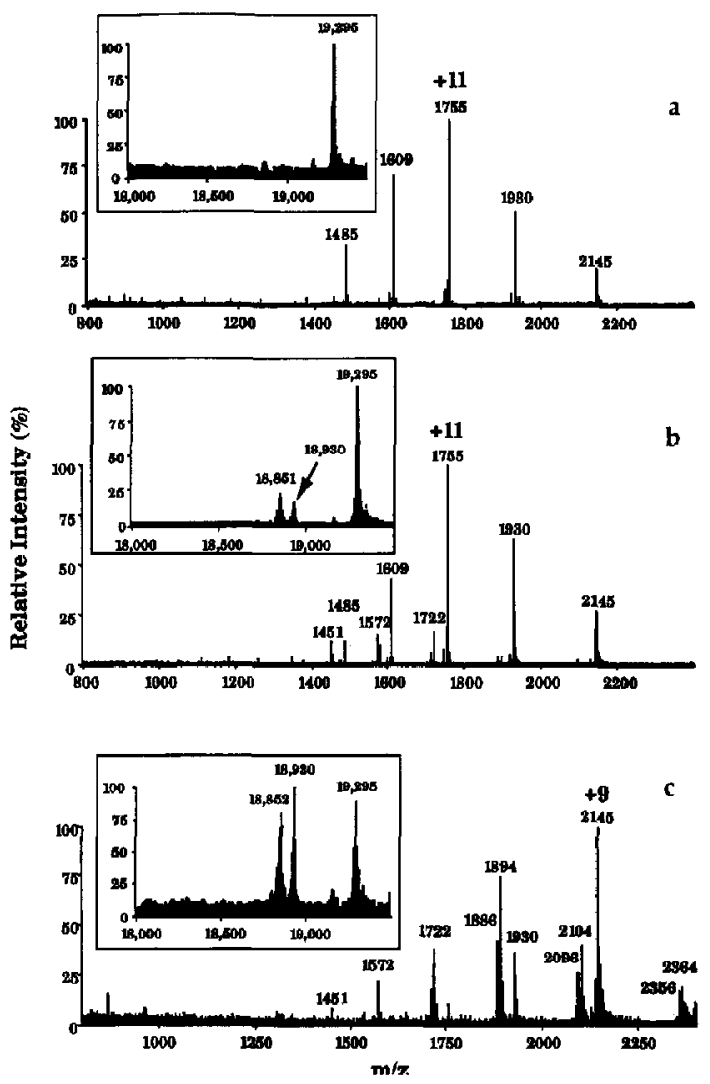

Figure 5. Full-scan ( $800-2400$ Da in $4 \mathrm{~s}$ ) ES mass spectra of the ras-GDP noncovalent complex obtained from aqueous solution with the $\mathrm{pH}$ adjusted to approximately 4.0 . The spectra were measured at different $O R$ settings: (a) $O R=40 \mathrm{~V}$, (b) 120, and (c) $200 \mathrm{~V}$. The corresponding deconvoluted spectra are presented in the insets (see text for discussion).

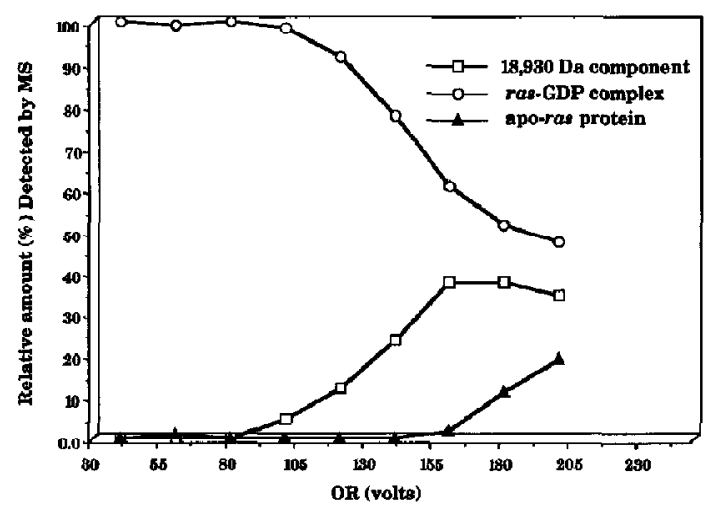

Figure 6. Effect of OR on the gas-phase ras-GDP noncovalent complex, showing the relative percentage of the three major components detected by mass spectrometry from a protein solution ( $\mathrm{pH} \sim 4$ ) at different orifice voltages. present time. Figure 6 shows the relative amount of these three components versus the experimental $O R$ setting. Evidently, the ras-GDP signal did not decrease until $\mathrm{OR}=80 \mathrm{~V}$. At $\mathrm{OR}=200 \mathrm{~V}$, the intact noncovalent complex of ras-GDP was still detected, and its ion intensity accounted for approximately $48 \%$ of the total protein signals. It was expected that the remaining protein would be detected as the dissociated apo-ras protein; however, to our surprise the apo-ras protein signal represented only $19 \%$, and the remaining $33 \%$ was accounted for by the $18,930-\mathrm{Da}$ component.

Careful consideration of all of the possible adducts observed in the ES mass spectrum revealed no meaningful information with regard to the identity of the 18,930 -Da component. The energy required to generate 18,930 -Da component from the complex was less than that required for stripping off the GDP from the protein complex in the gas phase, as indicated in Figure 6. The free form of the ras protein signal was not observed until OR reached approximately $155 \mathrm{~V}$, whereas the signal corresponding to the $18,930-\mathrm{Da}$ component increased linearly with $\mathrm{OR}$ as soon as OR was higher than $80 \mathrm{~V}$. The release of GDP under these conditions is considered not to be a result of the protein denaturation in solution, as commonly observed for both acidand organic solvent-induced protein denaturation [24, 25]. On the contrary, GDP was most likely knocked out from its binding pocket by means of a collision between the gas-phase ras-GDP complex and the $\mathrm{N}_{2}$ curtain gas. The implication of using this $O R$ voltage breakdown curve as an indication of association/dissociation measurement is very promising, even though its true correlation to the solution-phase noncovalent interaction requires further investigation.

\section{Conclusions}

We have successfully applied ES/MS to the detection of the noncovalent interaction of IFN- $\gamma$ dimer. The ability to use alkaline solution $(\mathrm{pH} \sim 9)$ is critical to this application. These results indicate that a protein-protein noncovalent complex can be desorbed, at or very close to its native solution conformation, as multiply charged ions and maintained in the gas phase.

Dissociation of the gas-phlase noncovalent complexes can be induced by increasing the OR voltage. In the two noncovalent complexes studied, the gas-phase rus-GDP complex required a substantial annount of energy to initiate the dissociation process, whereas the IFN- $\gamma$ dimer started to dissociate immediately following the $O R$ increase. The higher order conformation of the ras protein could still be preserved (or partially preserved) in the gas phase so that GDP is well protected in its binding pocket; hence more energy is required to dissociate the gas-phase ras-GDP complex. In contrast, the IFN- $\gamma$ dimer is composed of two identical protein subunits that are equally charged on ESI. 
Electrostatic repulsion between the charged subunits contributes to an inherently less stable noncovalent complex that is dissociated at a lower OR setting. In addition, the large cross section of the IFN- $y$ dimer increases the probability of effective collisions with gas molecules. It has been suggested [23] that covalent and noncovalent complexes observed under ESI can be easily differentiated by raising the OR. Our study of the gas-phase noncovalent complexes of ras-GDP and the IFN- $\gamma$ dimer, however, underscores the importance of careful use of this technique. The ES/MS technique could be extended further to study the complexes between proteins and other compounds of pharmaceutical interest. The extension of this research in probing the various kinetics of enzyme-substrate interactions is the subject of current research in our laboratory.

\section{Acknowledgment}

We thank Dr. L. Heimark for helpful discussions.

\section{References}

1. Lattimer, R. P.; Schulten, H. R. Anal. Chem. 1989, 61, 1201 A.

2. Barber, M.; Bordoli, R. S.; Sedgwick, R. D.; Tyler, A. N. I. Chem. Soc. Chem. Commun. 1981, 325.

3. Barber, M.; Bordoli, R. S.; Elliot, G. J.; Sedgwick, R. D.; Tyler, A. N. Anal. Chem. 1982, 54,645A.

4. Jonsson, G.; Hedin, A.; Hakansson, P.; Sundqvist, B.; Save, B. G. S.; Nielsen, P. F.; Roepstorff, P.; Johansson, K.-E.; Kamensky, I.; Lindberg, M. Anal. Chem, 1986, 58, 1084.

5. Macfarlane, R. D; Sundqvist, B. U. R. Mass Spectrom. Rev. $1985,4,421$.

6. (a) Cotter, R. Anal. Chem. 1988, 60, 781A; (b) Tsarbopoulos, A. Peptide Res. 1989, 2, 258.

7. Jonsson, G.; Hedin, A.; Hakansson, P.; Sundquist, B. U. R.; Bennich, H.; Roepstorff, P. Rapid Commun Mass Spectrom. 1989, 3, 190 .

8. Karas, M.; Hillenkamp, F. Anal Chem. 1988, 60, 2299.

9. Beavis, R. C.; Chait, B. T. Rapid Commun. Mass Spectrom. 1989, 3,4326 .

10. Fenn, J. B.; Mann, M.; Meng, C. K.; Wong, S. F.; Whitehouse, C. M. Science 1989, 246,64 .

11. Covey, T. R.; Bonner, R. F.; Shushan, B. I.; Henion, J. D. Rapid Commun. Mass Spectrom. 1988, 2, 249.

12. Loo, J. A.; Udseth, II. R.; Smith, R. D. Antl. Biotlien. 1989, $179,404$.

13. Carr, S. A.; Hemling, M. E.; Bean, M. F., Roberts, G. D., Anal. Chem. 1991, 63, 2802.
14. Bruins, A. P.; Covey, T. R.; Henion, J. D. Anal. Chem. 1987, $59,2642$.

15. Thomson, A. A.; Iribarne, J. V. J. Chem. Phys. 1979, 71, 4451.

16. Huang, E. C.; Wachs, T.; Conboy, J. J.; Henion, J. D. Anal. Chem. 1990, 62, 713A.

17. Covey, T. R.; Huang, E. C.; Henion, J. D. Anal. Chem. 1991, $63,1193$.

18. Loo, J. A.; Edmonds, C. G.; Smith, R. D. Anal. Chem. 1991, 63, 2488.

19. Feng, R.; Konishi, Y; Bell, A. W. I. Am. Sac. Mass Spectrom. $1991,2,387$.

20. Conboy. J. J.; Herion, J. D. J. Am. Soc. Mass Spectrom. 1992, 3, 804.

21. Ganem, B.; Li, Y.-T.; Henion, J. D. I. Am. Chem. Soc. 1991, 113,6294 .

22. Ganem, B.; Li, Y.-T.; Henion, J. D. J. Am. Chem. Soc. 1991, 113,7818 .

23. Baca, M.; Kent, B. J. Am. Chem. Soc, 1992, 114, 3992 ,

24. Ganguly, A. K.; Pramanik, B. N.; Tsarbopoulos, A.; Covey, T. R.; Huang, E. C.; Fuhrman, S. A. J. Am. Chem. Soc. 1992, 114,6559 .

25. Ganguly, A. K; Pramanik, B. N.; Huang, E. C.; Tsarbopoulos, A.; Girijavallabhan, V.; Liberles, S. Tetrahedron 1993, accepted.

26. Van Wauwe, J. P.; De Mey, J. R.; Goosens, J. G. J. Immunol. $1980,124,2708$.

27. Mulkerrin, M. G.; Wetzel, R. Biochemistry 1989, 28, 6556.

28. Le, H. V.; Mays, C. A.; Syto, S.; Nagabhushan, T. L.; Trotta, P. P. In The Biology of the Interferon System 1985: Stewart, W. E. II; Schellekens, H., Eds.; Elsevier; New York, 1985; P 73.

29. Lydon, N. B.; Faver, C.; Bove, S.; Neyret, O; Benureau, S; l.evine, A. M.; Seelig, G. S.; Nagabhushan, T. L.; Trotta, P. P. Biochemistry 1985, 24, 4131.

30. Bradford, M. Anal. Biochem. 1976, 72, 248

31. Ghrayeb, J.; Kimura, H.; Takahara, M.; Hsiung, H.; Masui, Y.; Inouye, M. EMBO J. 1984, 3, 2437.

32. Jacob, J.; Schlichting, I.; Schiltz, E.; Rösch, P.; Wittinghofer, A. I. Biol. Chem. 1989, 264, 13086.

33. Neal, S. L.; Lccleston, J. I.; I lall, A.; Webb, M. R. J. Biol. Chem. 1988, 263, 19718.

34. Tucker, J.; Sczakiel, G.; Feuerstein, J.; John, J.; Goody, R. S.; Wittinghofer, A. EMBO J. 1986, 5, 1351.

35. Henion, J. D.; Li, Y.-T; Ganem, B. Proceedings of the 40th ASMS Conference on Mass Spectrometry and Allied Topics; Washington, DC, May 31-June 5, 1992; p 1523.

36. Smith, R. D.; Loo, J. A.; Edmonds, C. G.; Barinaga, C. J.; Udseth, H. R. J. Chromatogr. 1990, 516, 157.

37. Kelly, M. A.; Vestling, M. M.; Fenselau, C. C.; Smith, P. B. Oro. Mass Spectront. 1992, 27, 1143.

38. Barbacid, M. Annu. Rev. Biochem. 1987, 56, 779.

39. Hall, A. Science 1990, 249, 635.

40. Marx, ]. Science 1992, 257, 484. 